\title{
Benzyl isothiocyanate sensitizes human pancreatic cancer cells to radiation by inducing apoptosis
}

\author{
MAKI OHARA $^{1,3}$, SHINICHI KIMURA ${ }^{1}$, AYA TANAKA ${ }^{1}$, KEN OHNISHI $^{2}$, \\ RYUICHI OKAYASU ${ }^{4}$ and NOBUO KUBOTA ${ }^{1}$
}

\begin{abstract}
${ }^{1}$ Department of Radiological Sciences and ${ }^{2}$ Department of Biology, Center for Humanity and Sciences, Ibaraki Prefectural University of Health Sciences, Ami, Inashiki-gun, Ibaraki 300-0394; ${ }^{3}$ Department of Environmental Sciences, Faculty of Science, Ibaraki University, Mito, Ibaraki 310-0035; ${ }^{4}$ Heavy-Ion Radiobiology Research Group, Research Center for Charged Particle Therapy, National Institute of Radiological Sciences, Inage-ku, Chiba 263-8555, Japan
\end{abstract}

Received June 20, 2011; Accepted July 27, 2011

DOI: $10.3892 / \mathrm{ijmm} .2011 .770$

\begin{abstract}
Isothiocyanates are a class of naturally occurring chemopreventive agents known to suppress proliferation of cancer cells in culture. The present study was undertaken in order to examine the effects of benzyl isothiocyanate (BITC), one of the common dietary isothiocyanates, on the radiosensitivity of human pancreatic cancer cells and to gain insights into the underlying molecular mechanism of BITC-induced radiosensitization. Two human pancreatic cancer cell lines, PANC-1 and MIAPaCa-2, were treated with BITC and irradiated with $\mathrm{X}$-rays. Radiation sensitivity, apoptosis, and protein levels were determined by a clonogenic assay, fluorescence microscopic analysis with DAPI staining and Western blotting, respectively. MIAPaCa-2 cells were relatively more sensitive to BITC treatment compared with PANC-1 cells. Radiosensitization was observed in both PANC-1 and MIAPaCa-2 cells incubated with BITC at 5 to $10 \mu \mathrm{M}$ and 2.5 to $5 \mu \mathrm{M}$ for $24 \mathrm{~h}$, respectively. The combination treatments with BITC and X-rays also revealed an increased percentage of apoptotic cells. In addition, treatment with BITC and X-rays resulted in a decrease in the protein levels of the X-linked inhibitor of apoptosis (XIAP), inhibitor of apoptosis (IAP) family protein, and in a marked increase in the apoptosis protease activating factor-1 (Apaf-1), essential for activation of caspase-9 in stress-induced apoptosis. BITC may be a useful radiosensitizer for radiotherapy of pancreatic cancers.
\end{abstract}

\section{Introduction}

In Japan and the United States, pancreatic cancer is respectively the fifth and fourth leading cause of cancer-related deaths (1).

Correspondence to: Dr Nobuo Kubota, Department of Radiological Sciences, Ibaraki Prefectural University of Health Sciences, 4669-2 Ami-machi, Ami, Inashiki-gun, Ibaraki 300-0394, Japan

E-mail: kubota@ipu.ac.jp

Key words: human pancreatic cancer cells, benzyl isothiocyanate, radiosensitization, apoptosis
Usually, pancreatic cancer is diagnosed at an advanced stage, therefore prognosis is very poor. Less than $5 \%$ of those diagnosed are still alive 5 years after diagnosis. Complete remission is still rather rare. Surgery remains the most effective treatment for pancreatic cancers. However, only $10-20 \%$ of cancers are suitable for tumor resection, after which local recurrences are common (2). Furthermore, pancreatic cancer cells have unusual resistance to both chemotherapy and radiotherapy $(3,4)$. These facts warrant development of novel therapeutic radiosensitizers for the treatment of pancreatic cancer.

Epidemiological studies have indicated that dietary intake of cruciferous vegetables may be protective against various types of cancers $(5,6)$. Isothiocyanates are degradation products of glucosinolates that are common in cruciferous vegetables including broccoli, watercress, cabbage and cauliflower (7). In addition to the chemopreventive properties, recent studies have shown that certain isothiocyanates can inhibit proliferation of cancer cells by inducing cell cycle arrest, apoptosis induction, and autophagic cell death $(8,9)$. Benzyl isothiocyanate (BITC), one of the best studied members of the isothiocyanate family, is of interest in cancer research due to suppression of cancer cell viability in association with cell cycle arrest, apoptosis induction, and autophagic cell death (10-14). In addition, BITC inhibits angiogenesis in vivo by down-regulation of vascular endothelial growth factor (VEGF) receptor 2 protein levels in the tumor (15). Based on these observations, it is considered that BITC is a promising candidate for further study in cancer prevention and therapy. Recently, it has been reported that BITC caused a significant decrease in the expression and activity of histone deacetylase (HDAC) 1 and HDAC 3 in human pancreatic carcinoma cells, but not in normal cells (16), indicating that BITC acts as a HDAC inhibitor in human pancreatic cells. Many laboratories have shown that HDAC inhibitors, including trichostatin A, MS-275 and Scriptaid sensitize human tumor cells to radiation $(17,18)$. The radiosensitizing effect of BITC has been reported recently against human pancreatic carcinoma cells (19). However, the mechanistic aspect underlying radiosensitization by BITC is not yet completely understood. Thus, the present study was undertaken to investigate the radiosensitization effect of BITC using PANC-1 and MIAPaCa-2 
human pancreatic cancer cells, in order to demonstrate that BITC enhances the responses of both cell lines to radiation by inducing apoptosis through caspase activation.

\section{Materials and methods}

Cell culture and chemicals. The human pancreatic tumor cell lines, PANC-1 and MIAPaCa-2, were maintained in $\alpha$-minimum essential medium ( $\alpha$-MEM) supplemented with $20 \mathrm{mM}$ 4-(2-hydroxyethyl) piperazine ethane sulfonic acid (HEPES), $8 \mathrm{mM} \mathrm{NaHCO}{ }_{3}, 50 \mu \mathrm{g} / \mathrm{ml}$ streptomycin, $50 \mathrm{U} / \mathrm{ml}$ penicillin and $10 \%$ fetal calf serum (20). Cells were cultured in a humidified incubator at $37^{\circ} \mathrm{C}$ with a mixture of $98 \%$ air and $2 \% \mathrm{CO}_{2}$. BITC was purchased from LKT Laboratories (St. Paul, MN, USA).

Irradiation. Cells were irradiated with $10 \mathrm{MV}$ X-rays from a linear accelerator (Mitsubishi Electric, Tokyo, Japan) at a dose rate of $4 \mathrm{~Gy} / \mathrm{min}$. Doses were measured using an Innax Dosemaster (NE Technology, Berks, UK) before irradiation.

Clonogenic assay. Cell survival for PANC-1 and MIAPaCa-2 cells was measured by a colony formation assay (21). Briefly, $10^{5}$ cells were seeded in $24 \mathrm{~cm}^{2}$ flasks and incubated for approximately $24 \mathrm{~h}$ before treatment with BITC. Cells were exposed to BITC or DMSO (control) for $16 \mathrm{~h}$, irradiated with $\mathrm{X}$-rays, and incubated in the presence of drug for a further $8 \mathrm{~h}$. After treatment with BITC for $24 \mathrm{~h}$, cells were washed with Dulbecco's phosphate-buffered saline (PBS) and dispersed with $0.05 \%$ trypsin containing $0.02 \%$ EDTA. Single cells were counted using a cell counter, diluted, and plated in $60-\mathrm{mm}$ dishes at various cell densities. The dishes were incubated in a $\mathrm{CO}_{2}$ incubator for 12 days. Colonies were stained with crystal violet dissolved in $20 \%$ methanol. Colonies of over 50 cells were counted as survivors.

Determination of apoptosis. Apoptosis induction was measured by detecting apoptotic bodies (22). PANC-1 and MIAPaCa-2 cells were exposed to BITC or DMSO for $16 \mathrm{~h}$, irradiated with 6 Gy of X-rays, and incubated in the presence of the drug for a further $8 \mathrm{~h}$. The medium was then removed and replaced with fresh medium free of drug. At $24 \mathrm{~h}$ after X-ray irradiation, both attached and floating cells were collected by trypsinization and centrifugation, resuspended in a fixative solution containing 3\% paraformaldehyde in PBS and stained with DAPI. The cells were placed on microscope slides and covered with glass coverslips. Then, the cells were photographed using a fluorescence microscope, and the number of apoptotic cells was counted.

Western blot analysis. Cells were exposed to BITC or DMSO for $16 \mathrm{~h}$, irradiated with $6 \mathrm{~Gy}$ of X-rays, and incubated in the presence of the drug for a further $8 \mathrm{~h}$. Cells were washed with ice-cold PBS, collected, and pelleted by centrifugation. Cells were lysed in lysis buffer (Cell Signaling Technology, Beverly, MA, USA) and then frozen and thawed three times. The cell lysates were centrifuged at $15,000 \mathrm{rpm}$ for $10 \mathrm{~min}$ at $4^{\circ} \mathrm{C}$. The protein concentrations of whole cell lysate supernatants were determined using a BCA protein assay kit (Pierce, Rockford, IL, USA). An equal amount of protein was then resolved on a 7.5\% SDS-polyacrylamide gel by electrophoresis and trans-

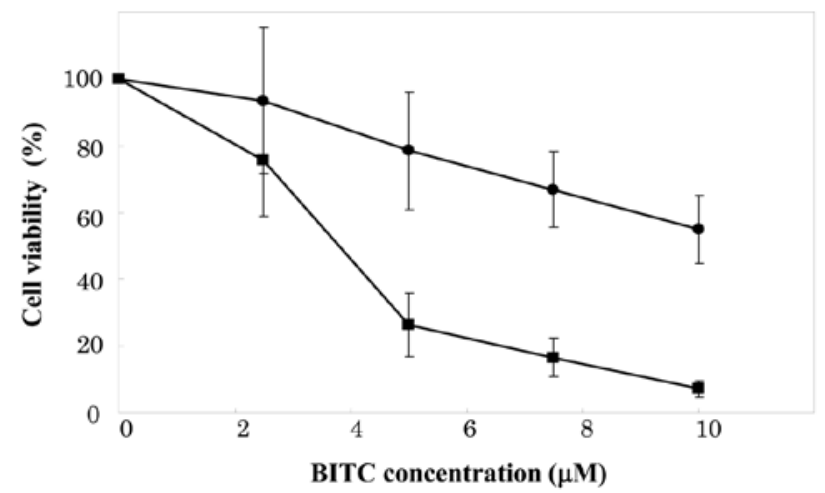

Figure 1. Effect of BITC on cell survival of PANC-1 (•) and MIAPaCa-2 (घ) cells. Cells were exposed to various concentrations of BITC for $24 \mathrm{~h}$ at $37^{\circ} \mathrm{C}$, and cell survival was measured by the colony formation method. Data points and bars are the average and standard errors, respectively, from three separate experiments.

ferred to polyvinylidene difluoride (PVDF) membranes using a semi-dry transfer system. The membranes were blocked in $5 \%$ non-fat milk for $1 \mathrm{~h}$ at room temperature, then incubated overnight at $4^{\circ} \mathrm{C}$ with a primary antibody specifically recognizing cleaved PARP, Bcl-2, Bax, apoptosis protease activating factor-1 (Apaf-1), X-linked inhibitor of apoptosis (XIAP) (Cell Signaling Technology), and actin (Chemicon International, Inc., Temecula, CA, USA). Primary antibodies were detected using the horseradish peroxidase (HRP)-conjugated second antibodies and an enhanced chemiluminescence (ECL) detection system (GE Healthcare, Buckinghamshire, UK).

\section{Results}

Effect of BITC on cell survival of human pancreatic tumor cells. To determine the effect of BITC on cell survival, PANC-1 and MIAPaCa- 2 cells, 2 human pancreatic cancer cell lines, were treated with increasing concentrations of BITC for $24 \mathrm{~h}$, and cell survival was assessed by a colony formation method. As shown in Fig. 1, BITC treatment resulted in concentrationdependent cell death in both cell lines.

Radiosensitization by BITC. To assess the effect of BITC treatment for $24 \mathrm{~h}$ on the radiosensitivity of PANC-1 and MIAPaCa- 2 cells, concentrations of 5 and $10 \mu \mathrm{M}$, and 2.5 and $5 \mu \mathrm{M}$ were used for PANC-1 and MIAPaCa-2 cells, respectively. Cell survival curves were constructed for both cell lines after X-ray irradiation in the presence or absence of BITC. Actively growing cells were exposed to BITC for $16 \mathrm{~h}$ at $37^{\circ} \mathrm{C}$, irradiated with $\mathrm{X}$-rays, and incubated for an additional $8 \mathrm{~h}$. Both cell lines showed significant increases in radiation-induced cell killing when combined with BITC treatment (Figs. 2 and 3). The radiosensitivity enhancement ratios measured at a survival rate of $10 \%$ were 1.19 at $5 \mu \mathrm{M}$ and 1.33 at $10 \mu \mathrm{M}$ in PANC- 1 cells, and 1.24 at $2.5 \mu \mathrm{M}$ and 1.63 at $5 \mu \mathrm{M}$ in MIAPaCa- 2 cells.

Effect of BITC on apoptosis induction. The apoptosis-inducing effect of BITC was examined using DAPI staining. The percentage of apoptotic cells after treatment with X-ray, BITC, or a combination of both is shown in Fig. 4A. The incidences 


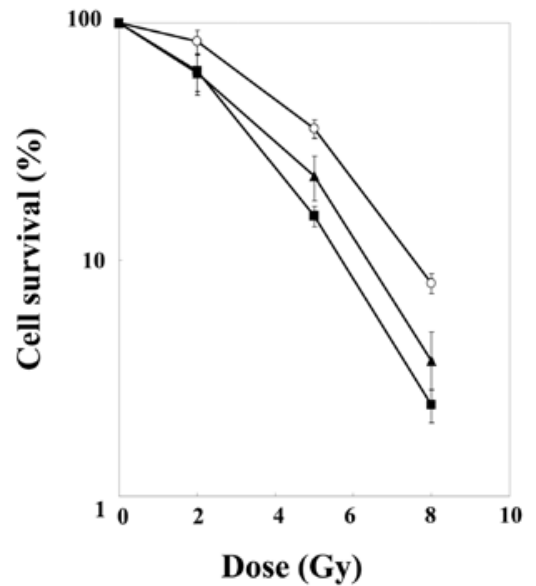

Figure 2. Radiosensitization of PANC-1 cells by BITC. No drug (O); $5 \mu \mathrm{M}$ BITC (₫) and $10 \mu \mathrm{M}$ BITC (ם). Cells were incubated with BITC for $16 \mathrm{~h}$ or not, irradiated with X-rays, and then incubated for a further $8 \mathrm{~h}$. Thereafter, cells were trypsinized, counted, and plated in $60 \mathrm{~mm}$ dishes. Points are means of three independent experiments. Error bars are standard errors of the mean.

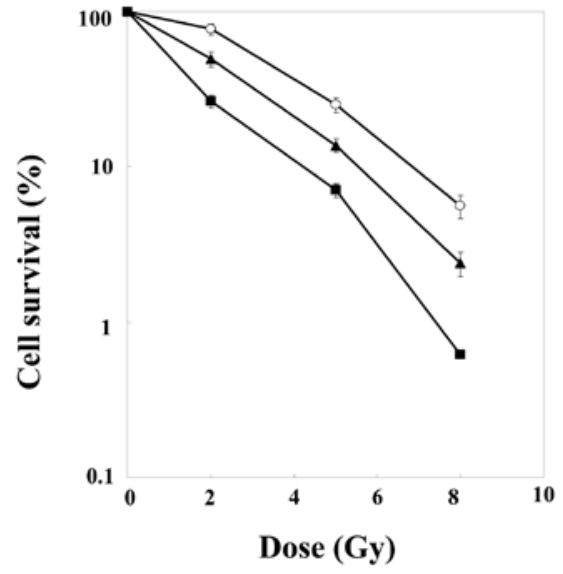

Figure 3. Radiosensitization of MIAPaCa-2 cells by BITC. No drug (O); $2.5 \mu \mathrm{M}$ BITC ( $(\mathbf{\bullet})$ and $5 \mu \mathrm{M} \mathrm{BITC}(\mathbf{\bullet})$. Cells were incubated with BITC for $16 \mathrm{~h}$ or not, irradiated with X-rays, and then incubated for a further $8 \mathrm{~h}$. Thereafter, cells were trypsinized, counted, and plated in $60 \mathrm{~mm}$ dishes. Points are means of three independent experiments. Error bars are standard errors of the mean.

\section{A}

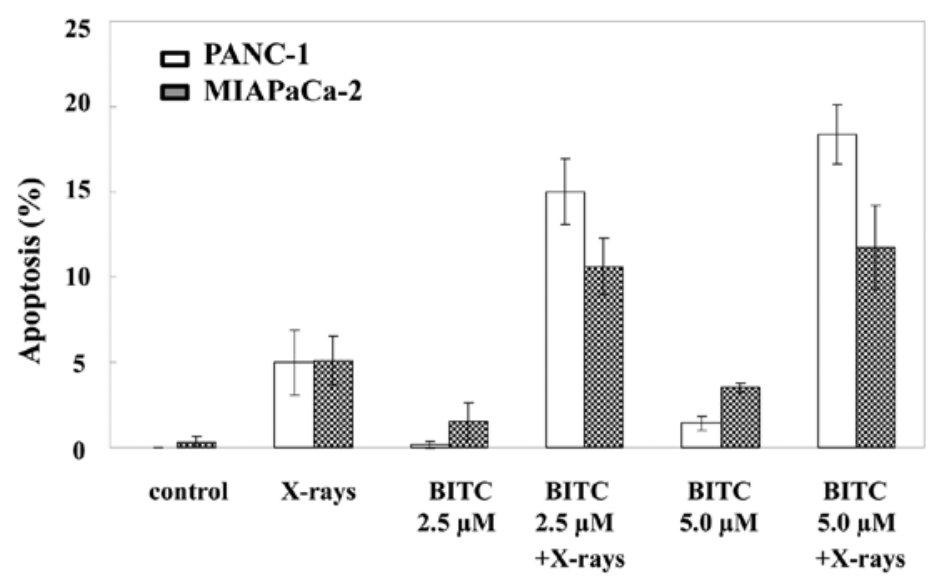

B

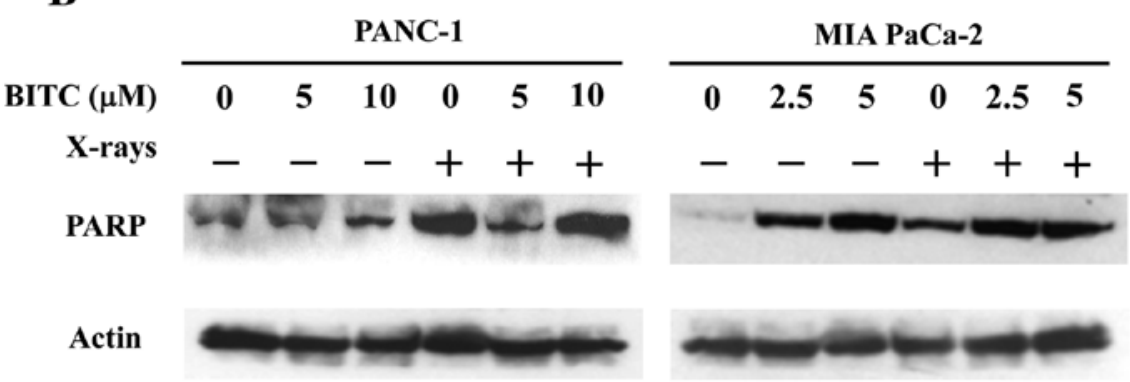

Figure 4. (A) Apoptosis in PANC-1 and MIAPaCa-2 cells exposed to X-rays with 6 Gy, with or without BITC. Apoptotic cells were measured 24 h after $\mathrm{X}$-irradiation. Error bars represent standard errors from more than three separate experiments. (B) Cleavage of PARP after exposure to BITC and/or X-ray irradiation. Cells were incubated with BITC for $16 \mathrm{~h}$ and then irradiated with X-rays of $6 \mathrm{~Gy}$, and incubated for a further $8 \mathrm{~h}$ at $37^{\circ} \mathrm{C}$. The medium was then removed and replaced with fresh medium free of drug. Cells were harvested $24 \mathrm{~h}$ after administration of X-rays and lysed. For detection of PARP, lysates were analyzed by Western blotting using an anti-cleaved PARP antibody.

of apoptosis in PANC-1 and MIAPaCa-2 cells were $~ 5 \%$ after $6 \mathrm{~Gy}$ of irradiation alone. When X-rays were combined with BITC at 2.5 or $5.0 \mu \mathrm{M}$, the percentage of apoptotic cells increased to $15-18 \%$ and $11-12 \%$ in PANC-1 and MIAPaCa-2 cells, respectively (Fig. 4A). The caspase family of aspartatespecific cysteine proteases critically mediates the cell death pathway. Of the caspase family, caspase- 3 is a common and important effector of the apoptotic process. The caspase-3 substrate, poly[ADP-ribose] polymerase (PARP), produces an 85-kDa fragment after caspase-3-mediated cleavage. BITC plus $\mathrm{X}$-irradiation increased the amount of cleaved PARP fragment in both PANC-1 and MIAPaCa-2 cells (Fig. 4B), indicating that caspase- 3 is activated after a combination of BITC and X-rays in both cells. 


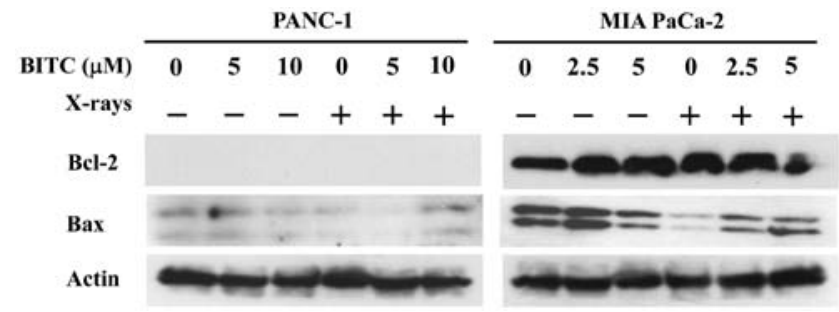

Figure 5. Expression levels of Bcl-2 and Bax in PANC-1 and MIAPaCa-2 cells treated with BITC with or without 6 Gy of irradiation with X-rays. Cell lysates were then prepared and equal aliquots of each lysate were analyzed by Western blotting. Bcl-2 and Bax proteins were visualized using antibodies as described in Materials and methods. Western blot analyses for actin are shown as loading controls.

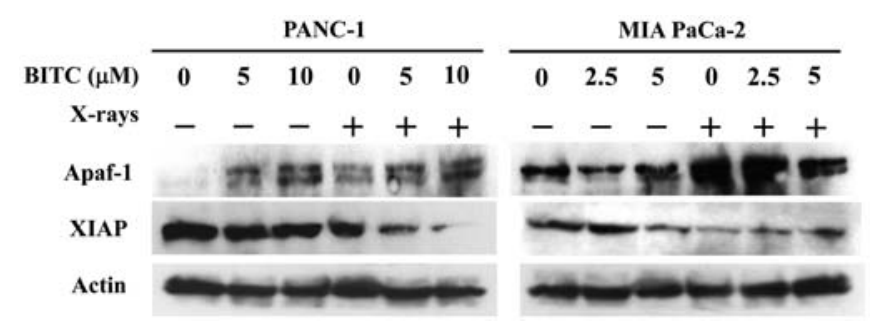

Figure 6. Expression levels of Apaf-1 and XIAP in PANC-1 and MIAPaCa-2 cells treated with BITC with or without 6 Gy of X-ray irradiation. Cell lysates were then prepared and equal aliquots of each lysate were analyzed by Western blotting. Apaf-1 and XIAP proteins were visualized using antibodies as described in Materials and methods. Western blot analyses for actin are shown as loading controls.

Effect of BITC on expression of apoptosis-related proteins. In PANC-1 cells, no expression of Bcl-2 and Bax was observed. In MIAPaCa-2 cells, protein levels of Bcl-2 remained essentially unchanged and Bax decreased after a combination of BITC and X-rays of 6 Gy (Fig. 5), indicating that Bcl-2 and Bax do not participate in the sensitization of apoptosis to X-rays by BITC.

Next, the effect of a combined treatment of BITC and X-rays on the level of Apaf-1 was determined (Fig. 6). Apaf-1 plays an important role in the regulation of apoptosis. A combined treatment of BITC and X-rays caused an increase in Apaf-1 in MIAPaCa-2 cells. It is well known that XIAP is the most potent inhibitor of apoptosis (IAP) bound to caspases. To determine if apoptosis induced by BITC and X-rays is associated with the levels of caspase inhibitor, we measured XIAP expression in PANC-1 and MIAPaCa- 2 cells after a combined treatment of X-rays and BITC. The levels of XIAP protein were markedly reduced upon treatment of PANC-1 cells with a combination of BITC and X-rays. These results suggest that sensitization of X-ray-induced apoptosis by BITC is associated with the up-regulation of Apaf-1 and down-regulation of XIAP in MIAPaCa-2 and PANC-1 cells, respectively.

\section{Discussion}

Although concurrent chemoradiotherapy has become common practice in treatment of locally advanced pancreatic cancers, its effect is modest because pancreatic cancer is relatively radioresistant, and clinically relevant and effective radiosensitizers for pancreatic cancer have rarely been reported (23). Extensive research in the last few years has revealed that regular consumption of certain fruits and vegetables can reduce the risk of acquiring specific cancers. Phytochemicals derived from such fruits and vegetables have been shown to suppress cancer cell proliferation, inhibit growth factor signaling pathways, and induce apoptosis, indicating that they may have untapped therapeutic value (24). Interestingly, our previous study showed that sulforaphane, an isothiocyanate (ITC) from broccoli and other cruciferous vegetables, significantly enhanced the radiosensitivity of human tumor cells in vitro and in vivo, in addition to showing repair inhibition of radiation-induced DNA double strand breaks (25). This repair inhibition seems to at least partially contribute to the enhanced apoptosis induced by the combination of radiation and sulforaphane, and led to the radiosensitization study with BITC using human pancreatic cancer cells.

The results of the present study demonstrate that BITC, a naturally occurring ITC present in cruciferous vegetables such as watercress, shows anti-proliferative activity in human pancreatic carcinoma MIAPaCa-2 and PANC-1 cells. It was found that BITC sensitized both pancreatic tumor cell lines to radiation. After exposure of cells to X-rays with BITC, a significant increase of apoptosis was observed compared to X-ray alone, indicating that the mechanisms underlying BITCinduced radiosensitization of cancer cells in part involve an increase in apoptosis.

Apoptosis is brought about by a family of proteases known as caspases. Two well-described pathways lead to caspase activation in mammalian cells: the extrinsic pathway triggered by an extracellular signal and the intrinsic pathway that responds to intracellular signals such as DNA damage, ischemia and oxidative stress (26). In the intrinsic pathway, mitochondria participate in apoptotic signaling pathways through the release of cytochrome c into the cytoplasm. Cytochrome $\mathrm{c}$ is the major inducer of caspase activation. Cytochrome $\mathrm{c}$ requires interaction with Apaf-1 for caspase activation. This promotes assembly of the apoptosome, a protein complex (consisting of Apaf-1, cytochrome $c$ and caspase-9) that functions to activate caspase-3 downstream of mitochondria in response to apoptotic signals $(27,28)$. IAPs are also potent regulators of cell death and survival (29). Of the IAPs, XIAP is the most potent inhibitor of caspase-9, -3 and -7 in mammalian cells (30). Elevated XIAP expression in variety of human cancers is thought to be responsible for the resistance to conventional therapeutic treatments including radiation therapy. Thus, XIAP has been considered a promising therapeutic target for the treatment of malignancy (31). A previous report revealed a complex signaling mechanism involving down-regulation of XIAP and Apaf-1 induction after treatment with sulforaphane, an ITC from broccoli and other cruciferous vegetables, in human tumor cells. In the present report, it was demonstrated that the levels of Apaf-1 protein were increased markedly upon treatment with a combination of BITC and X-rays in MIAPaCa- 2 cells. In addition, it was also found that expression of XIAP was decreased after combined treatment of BITC and $\mathrm{X}$-rays in PANC-1 cells. These results suggest that up-regulation of Apaf-1 and down-regulation of XIAP contribute to BITC-induced enhancement of apoptosis by radiation.

In a previous report, sulforaphane was demonstrated to significantly enhance apoptosis and radiosensitivity through impairment of repair pathways for radiation-induced DNA 
double strand breaks. The present study clearly indicated that radiation-induced apoptosis was enhanced by BITC treatment in human pancreatic tumor cells. The present data indicate that BITC, in addition to sulforaphane, have the potential to be used as adjuncts to current radiation therapy for pancreatic carcinoma.

\section{Acknowledgements}

This study was supported in part by a Grant-in-Aid for Scientific Research for the Promotion of Science (20591497).

\section{References}

1. Jemal A, Siegel R, Ward E, Murray T, Xu J, Smigal C and Thun MJ: Cancer statistics, 2006. CA Cancer J Clin 56: 106-130, 2006.

2. Gudjonson B: Cancer of the pancreas. 50 years of surgery. Cancer 60: 2284-2303, 1987.

3. DiMagno EP, Reber HA and Tempero MA: AGA technical review on the epidemiology, diagnosis, and treatment of pancreatic ductal adenocarcinoma. American Gastroenterological Association. Gastroenterology 117: 1464-1484, 1999.

4. Roy R and Maraveyas A: Chemoradiation in pancreatic adenocarcinoma: a literature review. Oncologist 15: 259-269, 2010.

5. Cohen JH, Kristal AR and Stanford JL: Fruit and vegetable intakes and prostate cancer risk. J Natl Cancer Inst 92: 61-68, 2000.

6. Verhoeven DT, Goldbohm RA, van Poppel G, Verhagen H and van den Brandt PA: Epidemiological studies on brassica vegetables and cancer risk. Cancer Epidemiol Biomarkers Prev 5: 733-748. 1996.

7. Fahet JW, Zalcmann AT and Talalay R: The chemical diversity and distribution of glucosinolates and isothiocyanates among plants. Phytochemistry 56: 5-51, 2001.

8. Zhang Y, Tang L and Gonzalez V: Selected isothiocyanates rapidly induce growth inhibition of cancer cells. Mol Cancer Ther 2: 1045-1052, 2003.

9. Bommareddy A, Hahm ER, Xiao D, Powolny AA, Fisher AL, Jiang Y and Singh SV: Atg5 regulates phenethyl isothiocyanateinduced autophagic and apoptotic cell death in human prostate cancer cells. Cancer Res 69: 3704-3712, 2009.

10. Miyoshi N, Uchida K, Osawa T and Nakamura Y: A link between benzyl isothiocyanate-induced cell cycle arrest and apoptosis: involvement of mitogen-activated protein kinases in the $\mathrm{Bcl}-2$ phosphorylation. Cancer Res 64: 2134-2142, 2004.

11. Zhang R, Loganathan S, Humphreys L and Srivastava SK Benzyl isothiocyanate-induced DNA damage causes G2/M cell cycle arrest and apoptosis in human pancreatic cells. J Nutr 136: 2728-2734, 2006.

12. Xiao D, Vogel V and Singh SV: Benzyl isothiocyanate-induced apoptosis in human breast cancer cells is initiated by reactive oxygen species and regulated by Bax and Bak. Mol Cancer Ther 5: 2931-2945, 2006

13. Srivastava SK and Singh SV: Cell cycle arrest, apoptosis induction and inhibition of nuclear factor kappa B human pancreatic cancer cells. Carcinogenesis 25: 1701-1709, 2004.
14. Sahu RP and Srivastava SK: The role of STAT-3 in the induction of apoptosis in pancreatic cancer cells by benzyl isothiocyanate. J Natl Cancer Inst 101: 176-193, 2009.

15. Warin R, Xiao D, Arlotti JA, Bommareddy A and Singh SV: Inhibition of human breast cancer xenograft growth by cruciferous vegetable constituent benzyl isothiocyanate. Mol Carcinog 49: 500-507, 2010 .

16. Batra S, Sahu RP, Kandaia PK and Srivastava SK: Benzyl isothiocyanate-mediated inhibition of histone deacetylase leads to NF-kappaB turnoff in human pancreatic carcinoma cells. Mol Cancer Ther 9: 1596-1608, 2010.

17. Kuribayashi T, Ohara M, Sora S and Kubota N: Scriptaid, a novel histone deacetylase inhibitor, enhances the response of human tumor cells to radiation. Int J Mol Med 25: 25-29, 2010.

18. Zhang Y, Jung M and Dritschilo A: Enhancement of radiation sensitivity of human squamous carcinoma cells by histone deacetylase inhibitors. Radiat Res 161: 667-674, 2004.

19. Sahu RP, Epperly MW and Srivastava SK: Benzyl isothiocyanate sensitizes human pancreatic cancer cells to radiation therapy. Front Biosci (Elite Ed) 1: 568-576, 2009.

20. Machida H, Nakajima S, Shikano N, Nishio J, Okada S, Asayama M, Shirai M and Kubota N: Heat shock protein 90 inhibitor 17-allylamino-17-demethoxygeldanamycin potentiates the radiation response of tumor cells grown as monolayer cultures and spheroids by inducing apoptosis. Cancer Sci 96: 911-917, 2005

21. Kubota N, Ozawa F, Okada S, Inada T, Komatsu K and Okayasu R: The phosphatidylinositol 3-kinase inhibitor wortmannin sensitizes quiescent but not proliferating MG-63 human osteosarcoma cells to radiation. Cancer Lett 133: 161-167, 1988.

22. Machida H, Matsumoto Y,Shirai M and Kubota N: Gendanamycin, an inhibitor of Hsp90, sensitizes human tumor cells to radiation. Int J Radiat Biol 79: 973-980, 2003.

23. El Maalouf G, Le Tourmeau C, Batty GN, Faivre S and Raymond E: Markers involved in resistance to cytotoxics and targeted therapeutics in pancreatic cancer. Cancer Treat Rev 35: 167-174, 2009.

24. Dorai T and Aggarwal BB: Role of chemopreventive agents in cancer therapy. Cancer Lett 215: 129-140, 2004.

25. Yu D, Sekine-Suzuki E, Xue L, Fujimori A, Kubota N and Okayasu R: Chemopreventive agent sulforaphane enhances radiosensitivity in human tumor cells. Int J Cancer 125: 1205-1211, 2009.

26. Taylor RC, Cullen SP and Martin SJ: Apoptosis: controlled demolition at the cellular level. Nat Rev Mol Cell Biol 9: 231-241, 2008.

27. Riedl SJ and Salvesen GS: The apoptosome: signaling platform of cell death. Nat Rev Mol Cell Biol 8: 405-413, 2007.

28. Bao O and Shi Y: Apoptosome: a platform for the activation of initiator caspases. Cell Death Differ 14: 56-65, 2007.

29. Deveraux QL and Reed JC: IAP family proteins - suppressors of apoptosis. Genes Dev 13: 239-252, 1999.

30. Kashkar H: X-linked inhibitor of apoptosis: chemoresistance factor or hollow promise. Clin Cancer Res 16: 4496-4502, 2010.

31. Shimmer AD, Dalili S, Batey RA and Riedl SJ: Targeting XIAP for the treatment of malignancy. Cell Death Differ 13: 179-188, 2006. 